\title{
Rancang Bangun Mesin Pencacah Plastik Tipe Gunting
}

\author{
Nuha Desi Anggraeni dan Alfan Ekajati Latief \\ Jurusan Teknik Mesin, Fakultas Teknologi Industri, ITENAS, Bandung \\ Email:nuha@itenas.ac.id
}

\begin{abstract}
ABSTRAK
Jumlah sampah plastik yang dibuang kelaut oleh Indonesia jumlahnya mendekati 200 juta ton. Jumlah ini berada di bawah Tiongkok yang menghasilkan sampah plastik mencapai 262,9 juta ton. Pada saat yang sama, kebutuhan akan plastik di Indonesia baru terpenuhi sekitar 64\% dari total 5 juta ton plastik. Sampah plastik yang dibuang kelaut, seharusnya dapat dimanfaatkan untuk memenuhi kebutuhan tersebut. Sampah plastik yang telah ada, perlu diolah agar dapat dimanfaatkan kembali sebagai plastik produksi. Pengolahan sampah plastik yang paling sederhana adalah dengan mencacah plastik yang telah ada menjadi serpihan-serpihan kecil menggunakan mesin pencacah. Mesin pencacah dapat digunakan dimanapun karena menggunakan mesin diesel sebagai penggeraknya. Mekanisme pencacahan yang digunakan menggunakan tipe gunting. Hasil perancangan mesin pencacah menggunakan 5 mata pisau dengan spesifikasi, panjang $180 \mathrm{~mm}$, lebar $50 \mathrm{~mm}$, tebal $10 \mathrm{~mm}$ dan sudut mata pisau $35^{\circ}$ dengan panjang poros penggerak $450 \mathrm{~mm}$, diameter 30 $\mathrm{mm}$.
\end{abstract}

Kata kunci:plastik, mesin, daur ulang.

\begin{abstract}
The amount of plastic waste discharged into the sea by Indonesia is approximately 200 million tons. This amount is below China which produces plastic waste reaches 262.9 million tons. At the same time, the need for plastics in Indonesia is only fulfilled about 64\% of the total 5 million tons of plastic. Plastic waste discharged into the sea, should be utilized to meet these needs. Plastic waste that has been there, needs to be processed in order to be reused as a production plastic. The simplest plastic waste processing is to chop the already existing plastic into small pieces. This chopper machine can be used anywhere because it uses a diesel engine as its propulsion. The enumeration mechanism used with scissor type. The design of the enumerator machine uses 5 blades with specifications, length of $180 \mathrm{~mm}$, width $50 \mathrm{~mm}, 10 \mathrm{~mm}$ thick and $35^{\circ}$ knife angle with $450 \mathrm{~mm}$ drive length, $30 \mathrm{~mm}$ diameter.
\end{abstract}

Keyword: plastic, machine, recycle 


\section{PENDAHULUAN}

Sampah plastik merupakan jenis sampah yang sangat sulit terurai dalam tanah, untuk menguraikan sampah plastik diperlukan waktu puluhan tahun. Pembuangan sampah plastik langsung di Tempat Pembuangan Akhir (TPA) akan menimbulkan masalah jika tidak dikelola dengan baik. Untuk itu, perlu dilakukan pengelolaan sampah plastik, mulai dari rumah tangga agar sampah dapat terolah dengan baik. Bentuk pengelolaan sampah plastik, dapat dimulai dengan melakukan pencacahan sampah tersebut agar mudah untuk didaur ulang. Pencacahan sampah plastik dapat dilakukan tanpa atau dengan menggunakan mesin. Penggunaan mesin pencacah untuk mencacah sampah plastik akan menghemat waktu pendaurulangan plastik, selain menjadikan sampah plastik tersebut bernilai jual tinggi.

Dengan menggunakan mesin pencacah ini, diharapkan dalam satu jam dapat mencacah plastik hingga $50 \mathrm{~kg}$. Untuk memudahkan perancangan, maka sampah plastik yang dapat dicacah pada mesin ini hanya plastik tipe polyethylene. Dengan mekanisme pencacahan crusher tipe gunting, untuk memudahkan pencacahan sampah plastik [1]. Pada penelitian ini, berhasil direalisasikan hasil perancangan baik poros dan mata pisau berserta dengan konstruksi yang mendukung mesin pencacah. Mesin diesel digunakan agar mesin dapat digunakan kapan saja dimana saja, pisau yang dihubungkan dengan poros juga dapat diganti sesuai dengan kebutuhan pencacahan [2]. Selainitu, mesin pencacah ini juga dapat dibongkar pasang dan dipindahkan.

\subsection{Metodologi Penelitian}

\section{METODOLOGI}

Perancangan mesin pencacah dilakukan mengikuti metodologi yang diuraikan pada gambar 1.

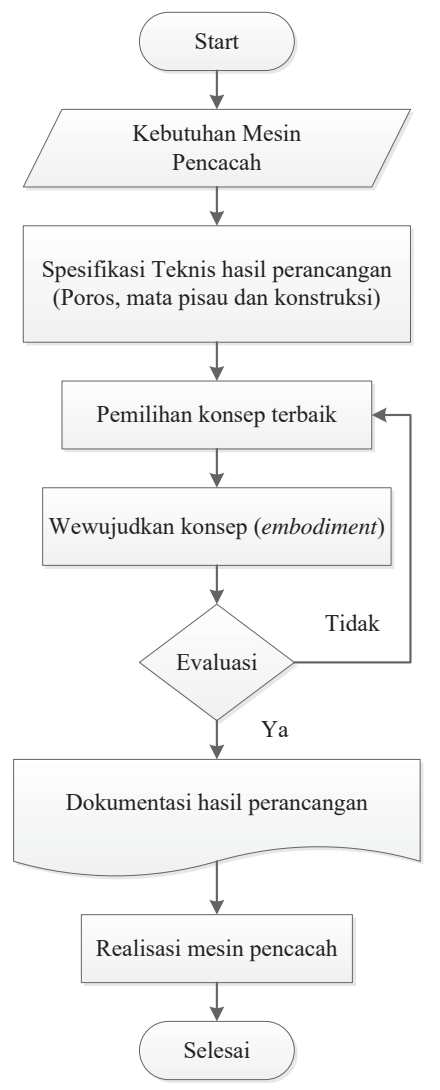

Gambar 1 Diagram alir rancang bangun mesin pencacah 


\subsection{Perancangan Poros dan Mata Pisau}

Untuk merealisasikan mesin pencacah, dilakukan perancangan mata pisau dan poros yang sesuai dengan kebutuhan pencacahan plastik, dan juga dapat diganti dengan mata pisau yang berbeda. Kapasitas mesin pencacah diharapkan mencapai $50 \mathrm{~kg}$ sampah plastik tercacah selama satu jam. Setelah dilakukan perancangan tersebut, konstruksi dirancang agar mesin pencacah dapat mudah dipindahkan. Skema daya untuk mesin pencacah ini diperlihatkan pada gambar 2, dengan mesin diesel digunakan sebagai penggeraknya.

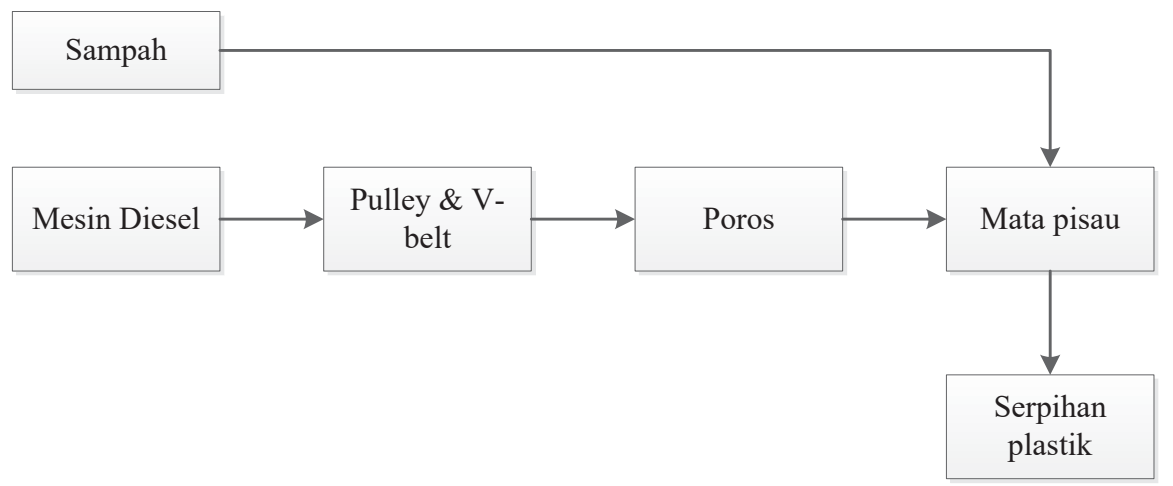

Gambar 2 Skema aliran daya [1]

Sudut ideal matapisau yang digunakan adalah $35^{\circ}$, untuk menghasilkan ketajaman matapisau yang sesuai dengan kebutuhan pengunaan di lapangan [3], mengikuti konsep mata pisau yang diuraikan pada tabel 1. Dari tabel 1 diketahui, semakin kecil sudut mata pisau maka pisau akan semakin tajam, selain itu gaya pemakanan yang diberikan pada plastik saat pencacahan sangat kecil.

Tabel 1 Konsep Mata Pisau[1]

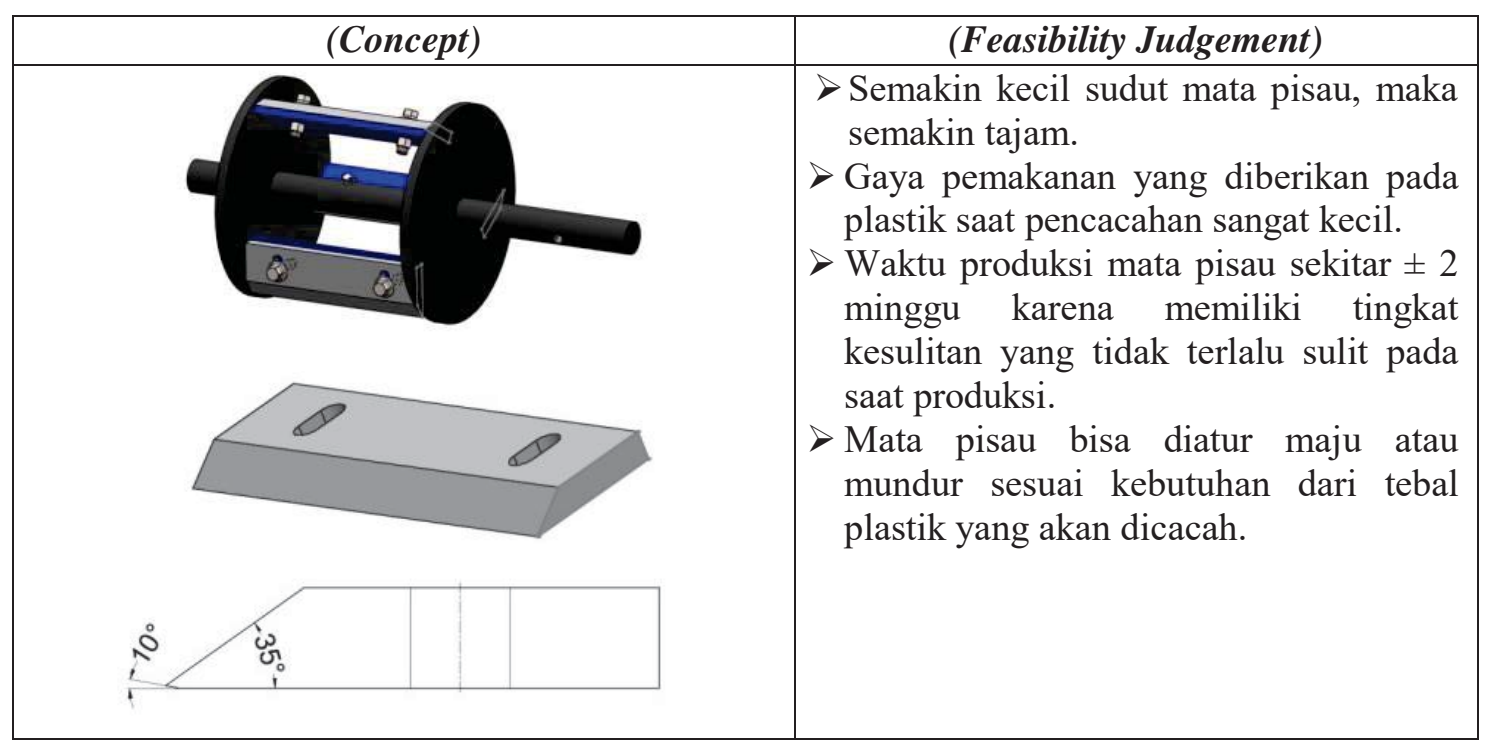

Mata pisau yang dirancang diharapkan dapat diatur maju dan mundur sesuai dengan kebutuhan tebal plastik yang akan dicacah. Tegangan geser maksimum untuk mata pisau nilainya adalah 589,38 $\mathrm{N} / \mathrm{mm}^{2}$. Baja karbon digunakan untuk pembuatan poros, karena pada bahan tersebut, tegangan yang terjadinya adalah $28,19 \mathrm{~kg} / \mathrm{mm}^{2}$. Bahan tersebut dipilih karena tegangan luluh (yield) bernilai 48 $\mathrm{kg} / \mathrm{mm}^{2}$, sehingga dapat disimpulkan bahwa bahan yang digunakan aman karena $\sigma_{\text {yield }}>\sigma_{\text {terjadi }}[4]$.

Spesifikasi teknis mesin pencacah awal diperlihatkan pada tabel 2. 
Tabel 2 Daftar Target SpesifikasiTeknis

\begin{tabular}{|c|l|l|}
\hline No & \multicolumn{1}{|c|}{ Spesifikasi Teknis } & \multicolumn{1}{c|}{ Target } \\
\hline $\mathbf{1}$ & Kapasitas & $50 \mathrm{~kg} / \mathrm{Jam}$ \\
\hline $\mathbf{2}$ & Faktor keamanan & Lebih dari 1 \\
\hline $\mathbf{4}$ & Daya motor & Max $5 \mathrm{HP}$ \\
\hline $\mathbf{5}$ & Dimensi minimum & $(1000 \times 1500 \times 225) \mathrm{mm}$ \\
\hline $\mathbf{6}$ & Transmisi penggerak & Transmisi sabuk \\
\hline $\mathbf{7}$ & Ukuran panjang plastik & $10 \mathrm{~mm}$ \\
\hline
\end{tabular}

\subsection{Perancangan Konstruksi Mesin}

Untuk mewujudkan konsep perancangan konstruksi mesin, perhitungan mekanikal elemen-elemen mesin pencacah plastik, dari rangka, sistem penggerak dan juga transmisinya [5]. Hasil perancangan konstruksi mesin diperlihatkan pada gambar 3.

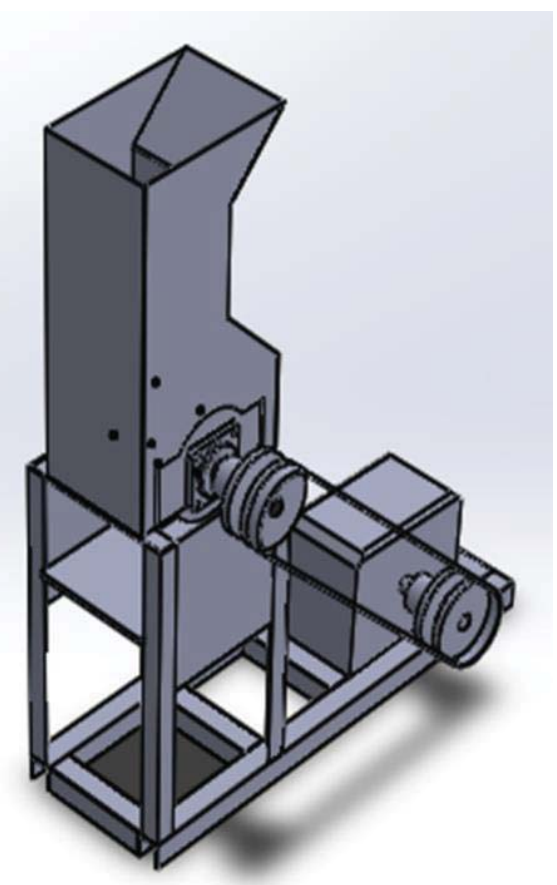

Gambar 3 Dokumentasi hasil perancangan

Dimensi hasil perancangan konstruksi mesin diperlihatkan pada tabel 3, dengan panjang $1000 \mathrm{~mm}$, lebar $225 \mathrm{~mm}$, tinggi $1500 \mathrm{~mm}$, dan jarak antar poros $500 \mathrm{~mm}$. Konstruksi ditambah dengan hopper berdimensi, panjang $335 \mathrm{~mm}$, lebar $260 \mathrm{~mm}$ dan tinggi $650 \mathrm{~mm}$. Sehingga dimensi konstruksi total adalah: panjang $1000 \mathrm{~mm}$, lebar $340 \mathrm{~mm}$ dan tinggi $1500 \mathrm{~mm}$. 


\section{HASIL DAN PEMBAHASAN}

Hasil perancangan mesin pencacah diperlihatkan pada tabel 3.

Tabel 3 Spesifikasi teknis hasil perancangan

\begin{tabular}{|c|c|c|}
\hline \multirow{3}{*}{ Poros } & Diameter & $30 \mathrm{~mm}$ \\
\hline & Panjang & $450 \mathrm{~mm}$ \\
\hline & Material & $\begin{array}{l}\text { S30C (Baja karbon konstruksi mesin) } \\
\tau_{\text {yield }}=48 \mathrm{~kg} / \mathrm{mm}^{2}\end{array}$ \\
\hline \multirow{3}{*}{ Mata pisau } & Dimensi & $180 \mathrm{~mm} \times 50 \mathrm{~mm} \times 10 \mathrm{~mm}$ \\
\hline & Jumlah mata pisau & 5 buah (3 statik, 2 dinamik) \\
\hline & Material & $\begin{array}{l}\text { Baja perkakas JIS SKD } 11 \\
\tau_{\mathrm{y}}=589,38 \mathrm{Mpa}\end{array}$ \\
\hline \multirow{3}{*}{ Dudukanmatapisau } & Dimensi & $176 \mathrm{~mm} \times 50 \mathrm{~mm} \times 8 \mathrm{~mm}$ \\
\hline & Jumlah & 3 buah \\
\hline & Material & $\begin{array}{l}\text { Baja perkakas JIS SKD } 11 \\
\tau_{\mathrm{y}}=589,38 \mathrm{Mpa}\end{array}$ \\
\hline \multirow{5}{*}{ Piringan } & Diameter luar & $200 \mathrm{~mm}$ \\
\hline & Diameter dalam & $30 \mathrm{~mm}$ \\
\hline & Tebal & $10 \mathrm{~mm}$ \\
\hline & Jumlah piringan & 2 buah \\
\hline & Material & $\begin{array}{l}\text { Baja perkakas JIS SKD } 11 \\
\tau_{\mathrm{y}}=589,38 \mathrm{Mpa}\end{array}$ \\
\hline \multirow{4}{*}{ Pasak } & Jenispasak & Pin \\
\hline & Panjang & $90 \mathrm{~mm}$ \\
\hline & Diameter pin & $10 \mathrm{~mm}$ \\
\hline & Material & $\begin{array}{l}\text { Baut baja karbon rendah ASTM A307 } \\
\left(\tau_{\mathrm{y}}=60 \mathrm{MPa}\right)\end{array}$ \\
\hline \multirow{3}{*}{ Hopper } & Panjang & $335 \mathrm{~mm}$ \\
\hline & Lebar & $260 \mathrm{~mm}$ \\
\hline & Tinggi & $650 \mathrm{~mm}$ \\
\hline \multirow{4}{*}{ Konstruksi } & Tebal canal & $5 \mathrm{~mm}$ \\
\hline & Panjang & $1000 \mathrm{~mm}$ \\
\hline & Lebar & $340 \mathrm{~mm}$ \\
\hline & Tinggi & $1500 \mathrm{~mm}$ \\
\hline \multirow{3}{*}{ Kapastitas transmisi } & Daya & $3,3 \mathrm{~kW} / 4,5 \mathrm{HP}$ \\
\hline & Daya rencana & $6,27 \mathrm{~kW}$ \\
\hline & Daya motor diesel & $5 \mathrm{HP}$ \\
\hline
\end{tabular}

Konsep sudut ideal mata pisau adalah $35^{\circ}-45^{\circ}$, sudut mata potong $10^{\circ}$, pada penelitian ini digunakan sudut $35^{\circ}$. Nilai maksimum momen lentur adalah 54606,4 Nmm, yang diakibatkan oleh beban yang terjadi pada komponen mata pisau dan gaya-gaya pemotongan mata pisau. Diameter poros rencana adalah $30 \mathrm{~mm}$, torsinya bernilai $60192 \mathrm{Nmm}$, sehingga tegangan poros yang terjadi adalah 28,19 $\mathrm{kg} / \mathrm{mm}^{2}[6]$. Sehingga pemilihan bahan poros S30C (baja karbon konstruksi) yang memiliki $\sigma_{\mathrm{y}}=48$ $\mathrm{kg} / \mathrm{mm}^{2}$, aman saat digunakan.

Transmisi pulley yang digunakan adalah tipe $\mathrm{V}$ alur tunggal dengan ukuran diameter penggerak 100 $\mathrm{mm}$ dan diameter pulley yang digerakkan $150 \mathrm{~mm}$. Daya yang dibutuhkan adalah 4,5 HP, sehingga digunakan mesin diesel dengan daya 5 HP. Desain hopper meliputi safety factor dan kemudahan memasukkan sampah plastik yang akandicacah [7]. 


\section{KESIMPULAN}

Mata pisau, poros dan konstruksi yang dirancang telah berhasil digunakan untuk mencacah plastik sesuai dengan rencana perancangan. Mesin pencacah yang dibuat telah berfungsi dengan baik, hanya perlu dilakukan pengujian untuk menentukan kapasitas pencacahan dan kinerja mesin. Mesin diesel yang digunakan dapat diganti dengan mesin penggerak lain selama daya yang ditransmisikan nilainya lebih dari 4,5 HP (3,3 kW). Mesin pencacah ini masih dapat dimodifikasi sesuai dengan kebutuhan.

\section{DAFTAR PUSTAKA}

[1] A. E. Latief, N. D. Anggraeni and A. Sulaeman, "Perancangan Poros dan Mata Pisau Mesin Pencacah Plastik," in Seminar Nasional Tahunan Teknik Mesin ke-15, Bandung, 2016.

[2] A. E. Latief, N. D. Anggraeni and D. J. Hermawan, "Perancangan Konstruksi Mesin Pencacah Plastik," in Seminar Nasional Tahunan Teknik Mesin XV, Bandung, 2016.

[3] G. E. Dieter, Mechanical Metallurgy, New York: McGraw-Hill, 1992.

[4] Sularso and K. Suga, Perencanaan dan Pemilhan Elemen Mesin, 1991.

[5] Harsokoesoemo, Pengantar Perancangan Teknik (Perancangan Produk), Bandung: Institut Teknologi Bandung, 2004.

[6] N. D. Anggraeni and A. E. Latief, "Modifikasi Mata Pisau Mesin Pencacah Plastik Tipe Polyethylene," in Seminar Nasional Rekayasa dan Aplikasi Teknik Mesin di Industri, Bandung, 2017.

[7] R. G. Budynas, Shigley's mechanical engineering design 9th edition, New York: McGraw-Hill, 2008. 